\title{
Perencanaan Pembangunan WAN Menggunakan EIGRP Dynamic Routing
}

\author{
Slamet Riyadi ${ }^{[1]^{*}}$, Ade Surya Budiman ${ }^{[2]}$ \\ Prodi Teknik Informatika ${ }^{[1]}$, Prodi Teknologi Komputer, UBSI ${ }^{[2]}$ \\ STMIK Nusa Mandiri ${ }^{[1]}$, Universitas Bina Sarana Informatika ${ }^{[2]}$ \\ DKI Jakarta, Indonesia \\ slamet.silvia.sr@gmail.com ${ }^{[1]}$,ade.aum@bsi.ac.id ${ }^{[2]}$
}

\begin{abstract}
The development of company's business area will have implications for the development of computer network infrastructure as a means of exchanging data and information between regions. As a company that continues to develop its business area, PT. Timur Raya Lestari requires a computer network infrastructure that is adaptive to the development of the number of branch offices. The company's computer network currently uses the Static Routing method in determining the interconnection path between Routers connecting the head office and branch offices. The development of a dynamic company must be accompanied by the development of a dynamic network infrastructure as well. Development of a network infrastructure that continues to develop requires Dynamic Routing Protocol. In this study, it was simulated the use of EIGRP as Dynamic Routing Protocol for PT. Timur Raya Lestari. From the simulation results using Cisco Packet Tracer software, it can be seen that there is a stable interconnection, both for existing networks plan and planning for adding networks on new branch offices.
\end{abstract}

Keywords - Network Infrastructure, Dynamic Routing Protocol, EIGRP

\begin{abstract}
Abstrak - Pengembangan wilayah bisnis perusahaan akan berimplikasi kepada pengembangan infrastruktur jaringan komputer sebagai sarana pertukaran data dan informasi antar wilayah. Sebagai perusahaan yang terus mengembangkan wilayah bisnisnya, PT. Timur Raya Lestari membutuhkan infrastruktur jaringan komputer yang adaptif terhadap perkembangan jumlah kantor cabang. Jaringan komputer perusahaan saat ini menggunakan metode Static Routing dalam penentuan jalur (path) interkoneksi antar Router yang menghubungkan jaringan kantor pusat dan kantor cabang. Perkembangan perusahaan yang dinamis, harus disertai dengan pengembangan infrastruktur jaringan yang dinamis pula. Pengembangan infrastruktur jaringan yang terus berkembang tersebut membutuhkan Dynamic Routing Protocol. Dalam penelitian ini, disimulasikan penggunaan EIGRP sebagai Dynamic Routing Protocol untuk jaringan PT. Timur Raya Lestari. Dari hasil simulasi menggunakan perangkat lunak Cisco Packet Tracer, terlihat adanya interkoneksi yang stabil, baik perencanaan untuk jaringan yang sudah ada maupun untuk rencana penambahan jaringan pada kantor cabang baru.
\end{abstract}

Kata Kunci - Infrastruktur Jaringan, Dynamic Routing Protocol, EIGRP

\section{PENDAHULUAN}

Pengembangan wilayah bisnis perusahaan, berarti pembentukan jaringan (network) yang baru atau dengan kata lain adalah pengembangan infrastruktur jaringan komputer yang baru. Didalam konsep jaringan komputer, interkoneksi antar jaringan berhubungan dengan lapisan Network (Network Layer), yang berisikan serangkaian proses yang bertanggung jawab dalam proses transmisi data antar jaringan (network) yang berbeda.

PT. Timur Raya Lestari merupakan perusahaan yang menjalankan bisnis penjualan dan pembuatan produk lensa dan frame kacamata. Teknologi Informasi tidak dapat dipisahkan dari proses bisnis perusahaan, satu diantaranya adalah jaringan komputer. Jaringan komputer sangat dibutuhkan oleh perusahaan karena setiap komputer dan mesin melakukan pertukaran data (komunikasi data) melalui infrastruktur yang ada.

Dalam proses bisnisnya, perusahaan dibantu oleh beberapa kantor cabang yang tersebar di beberapa provinsi di Indonesia, Kantor/lokasi cabang dijadikan sebagai kantor dan tempat pemasaran bisnis perusahaannya. Menyertai fungsinya, setiap kali dilakukan penambahan kantor cabang, maka akan diperlukan penambahan infrastruktur jaringan komputer yang baru yang dapat terhubung dengan infrastruktur jaringan komputer yang sudah ada (existing network) pada perusahaan ini, supaya setiap kantor cabang dapat melakukan pertukaran data atau informasi baik dari cabang ke cabang dan cabang ke kantor pusat, maupun sebaliknya.

Akan tetapi saat ini metode pengembangan jaringan masih menggunakan static routing yang kurang fleksibel jika dipergunakan pada jaringan yang besar dan terus berkembang. Sehingga perlu dilakukan perencanaan dan desain untuk menggunakan metode dynamic routing yang lebih umum dipergunakan dalam membangun jaringan komputer yang besar dan terus berkembang.

\section{TELAAH LITERATUR}

\section{A. Routing Protocol}

Pengembangan jaringan komputer seperti yang 
disampaikan dalam pendahuluan, tidak dapat dipisahkan kaitannya dengan perangkat yang terdapat pada Core Layer dalam hierarki jaringan komputer. Dalam model hierarki, infrastruktur jaringan komputer dibentuk interkoneksinya dengan memanfaatkan kemampuan perangkat $3 \mathrm{rd}$ layer (Network Layer) sebagai tulang punggung atau inti lalu lintas komunikasi data antar lokasi (site) saat pertukaran atau transmisi data dilakukan.

Perangkat Network Layer yang ditugaskan untuk menjadi penghubung antar jaringan dalam hal ini adalah Router. Router memiliki fungsi utama untuk menghubungkan beberapa network yang berbeda dan menemukan jalur terbaik (best path) untuk mengirimkan data dari sumber data menuju ke tujuan data, misalnya dalam proses file sharing, file transfer, video conferencing, voice conferencing [1][2][3].

Dalam beberapa penelitian terdahulu, telah diteliti dan dibahas terkait dengan bagaimana interkoneksi jaringan komputer. Diantaranya adalah untuk membangun jaringan komputer di kampus Universitas Islam Riau berbasis dynamic routing EIGRP, dimana nilai throughput dan delay telah memenuhi standar ITU-TG.114[4]. Dalam skala Enterprise yaitu pada PT. AIA Financial, desain jaringan WAN untuk beberapa lokasi kantor cabang juga dapat diterapkan dengan baik dengan menggunakan salah satu protokol dynamic routing yaitu EIGRP[5].

Dalam menjalankan fungsinya sebagai pencari dan penentu arah (route) dalam proses transmisi data, setiap Router yang terdapat dan saling terhubung dalam jaringan, akan berkomunikasi satu sama lain dengan cara saling bertukar informasi rute (route exchange) yang secara teknis disimpan dalam sebuah tabel yang dinamakan routing table.

Routing table berisikan informasi yang dibutuhkan oleh sebuah Router untuk memahami rute selanjutnya untuk mengirimkan data dari sumber hingga sampai ke tujuan data, Router akan mengirimkan paket data yang diterimanya ke Router terdekatnya atau Neighbour Router. Router akan menentukan pengiriman paket data ke router yang mana, berdasarkan informasi yang terdapat didalam routing table tersebut. Proses ini di ilustrasikan dalam Gambar 1.

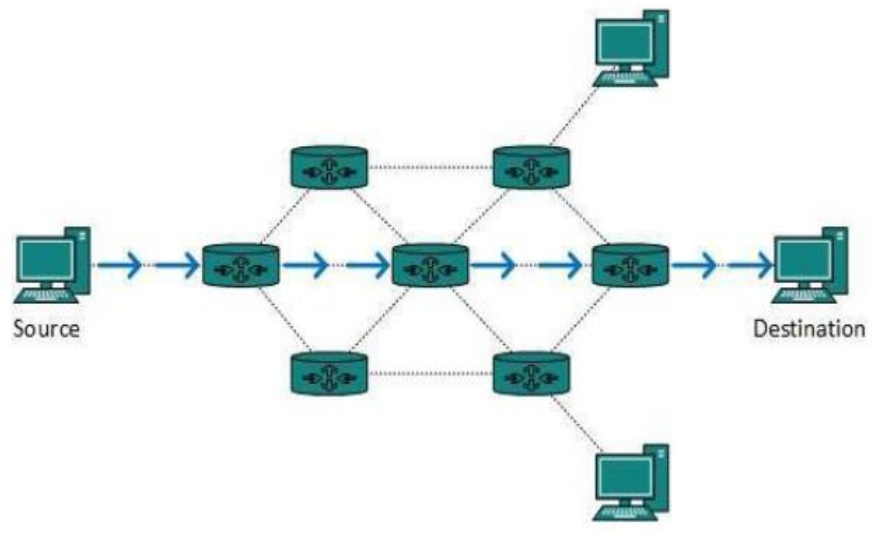

Gambar 1. Ilustrasi Trasmisi Paket Data Oleh Router [6]

Mekanisme pengisian informasi dalam routing table dapat dibagi kedalam dua jenis, yaitu (i) static routing dan (ii) dynamic routing. Static routing merupakan mekanisme pengisian informasi mengenai arah router berikutnya (next hop) yang diatur secara manual dan ditetapkan arahnya oleh seorang administrator jaringan komputer. Dengan demikian, setiap perubahan arah apapun, harus melalui perubahan konfigurasi yang dilakukan secara manual oleh administrator[7]. Ketika jaringan memiliki 3 atau lebih router, maka konfigurasi yang harus diberikan semakin banyak dan akan memperberat tugas seorang adminstrator, maka dibutuhkan metode Dynamic Routing [8].

Berbeda halnya dengan Static Routing, dimana setiap Router diberikan perintah untuk menghasilkan routing table sendiri secara otomatis [9]. Mekanisme dynamic routing sangat dibutuhkan untuk jaringan komputer yang memiliki jangkauan jaringan yang besar dan luas, serta memiliki potensi perubahan bentuk infrastruktur jaringan komputer yang besar.

Dynamic routing protocol terbagi kedalam sejumlah protokol berdasarkan prinsip dan cara kerjanya, diantaranya Routing Information Protocol (RIP), Open Shortest Path First (OSPF), Enhanced Interior Gateway Routing Protocol (EIGRP), Intermediary System (IS-IS) dan Border Gateway Protocol (BGP).

Untuk melihat atau menentukan keunggulan dan kelebihan dari masing-masing protokol dynamic routing, perlu dilakukan pengukuran dengan menggunakan indikator tertentu, seperti delay, throughput, packet delivery, load, dan Ethernet Delay. Menggunakan OPNET Simulator tool, sebagai alat bantu pengukuran, disimpulkan bahwa EIGRP dan OSPF merupakan protokol yang paling disarankan untuk jaringan skala Enterprise, institusi pendidikan dan kawasan industri[10]. EIGRP juga diunggulkan karena memiliki konvergensi yang lebih cepat dan penggunaan bandwidth yang lebih efisien apabila dibandingkan dengan RIP dan OSPF, sehingga cocok untuk jaringan skala besar maupun kecil[11].

Meskipun demikian dari aspek biaya trasmisi, OSPF memiliki biaya paling kecil dibandingkan dengan EIGRP, IGRP dan RIP[12]. Akan tetapi EIGRP unggul pula dalam pemilihan jalur dibandingkan dengan OSPF, sehingga dapat melakukan perpindahan data dengan lebih cepat, kendati Quality of Service (QoS) keduanya sebanding[7].

EIGRP merupakan protocol yang dikembangkan oleh Cisco sebagai peningkatan dari Interior Gateway Routing Protocol (IGRP), yang memungkinkan informasi dibawa lebih banyak mengenai jalur yang dipakai untuk mengirimkan data, seperti Bandwidth, Delay, Load, Maximum Transmission Unit (MTU) dan Reliablity [13]. IGRP sendiri merupakan perbaikan dari protokol RIP yang menentukan jalur (path) pengiriman data berdasarkan pencacahan lompatan (hop count) antar Router untuk sampai ke tujuan data atau dengan kata lain, berapa Router yang harus dilewati sebelum sampai ke tujuan. Sebagai penerus dari IGRP, EIGRP memungkinkan penambahan informasi mengenai subnet mask (sudah mengenal konsep classless) serta mampu mengurangi waktu konvergensi yang dapat mempercepat pertukaran data dan informasi routing antar router. 


\section{METODE PENELITIAN}

Untuk mendapatkan data primer mengenai kondisi jaringan berjalan dan analisa terhadap kebutuhan pengguna dan jaringan, penulis melakukan serangkaian observasi dan wawancara terhadap stakeholder terkait dari PT. Timur Raya Lestari. Sebagai data pelengkap dan penunjang, penulis melakukan literature review terhadap sejumlah penelitian terdahulu.

Mengacu kepada konsep Network Design Methodologies [14], penulis membagi tahapan desain jaringan kedalam tiga langkah berikut:

1. Identifikasi Kebutuhan Jaringan

2. Pengenalan Karakter Jaringan Berjalan

3. Desain Topologi Jaringan dan Solusi.

\section{HASIL DAN PEMBAHASAN}

\section{A. Identifikasi Kebutuhan}

Dalam proses pertumbuhan bisnis di PT. Timur Raya Lestari, penerapan infastruktur menggunakan static routing tidak tepat untuk perkembangan bisnis perusahaan, dikarenakan static routing tidak optimal untuk infrastruktur jaringan yang besar dan berkembang terutama dengan pertimbangan perusahaan yang berencana untuk terus membuat kantor cabang baru di beberapa wilayah di indonesia. Secara skematik, jaringan harus dapat disesuaikan dengan perkembangan dan perluasan organisasi perusahaan. Untuk itu perlu metode yang memungkinkan proses routing berjalan secara efektif dan efisien.

\section{B. Karakteristik Existing Network}

Dalam gambar 2 diperlihatkan skema jaringan yang saat ini berjalan (existing network) di PT. Timur Raya Lestari. Kantor pusat di Jakarta merupakan lokasi dimana sejumlah server ditempatkan, diantaranya: Server Lensware, Server Basis Data, Server Web dan Server E-mail.

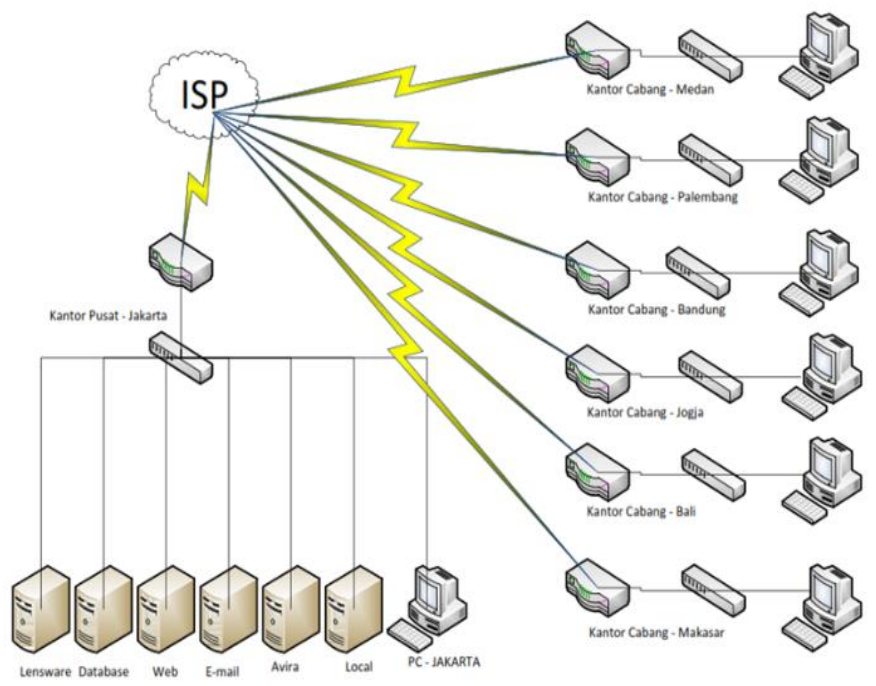

Gambar 2. Skema Existing Network

\section{Desain Jaringan Usulan}

Secara skema dan topologi, existing network tidak mengalami perubahan. Perubahan mendasar hanya dilakukan pada konfigurasi Router di masing-masing lokasi, dari sebelumnya menggunakan static routing, diganti dengan dynamic routing, yang dalam hal ini menggunakan protokol Enhanced Interior Gateway Routing Protocol (EIGRP). Hal ini untuk memudahkan konfigurasi secara umum pada Router, jika terjadi pembukaan kantor cabang baru. Desain jaringan usulan dan simulasinya dilakukan dengan bantuan perangkat lunak Cisco Packet Tracer.

\section{Konfigurasi Jaringan Di Beberapa Lokasi}

1) Konfigurasi Router Pada Jaringan Kantor Pusat Jakarta.

Berikut merupakan konfigurasi yang diberikan pada Router yang terdapat di Kantor Pusat Jakarta.

Diawali dengan perintah untuk masuk ke Privilidge Exec Mode pada Cisco IOS yang terdapat pada Router di sisi Kantor Pusat Jakarta untuk melakukan serangkaian konfigurasi yang diperlukan.

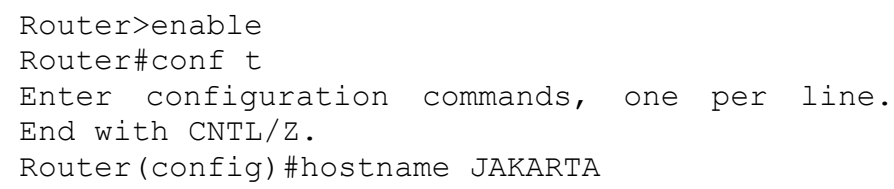

Berikutnya adalah melakukan konfigurasi pada interface yang akan menjadi Gateway dengan memberikan alamat Gateway dan mengaktifkan Interface tersebut.

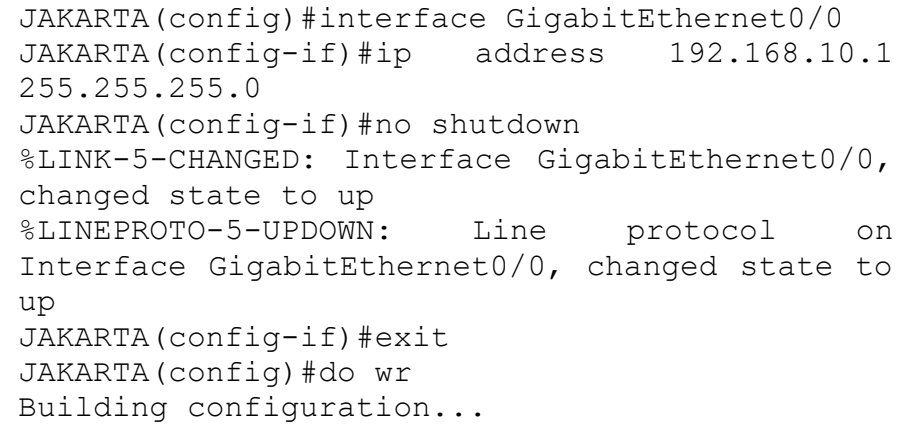

Langkah berikutnya adalah mengaktifkan interface pada sisi yang mengarah menuju seluruh kantor cabang (6 lokasi) dengan rangkaian konfigurasi dibawah ini. Dengan alamat interface masing-masing adalah:

1. Interface Serial $0 / 0 / 0$

Alamat: 172.16.2.2 255.255.0.0

2. Interface Serial $0 / 0 / 1$

Alamat: 172.17.2.2 255.255.0.0

3. Interface Serial $0 / 1 / 0$

Alamat: 172.18.2.2 255.255.0.0

4. Interface Serial 0/1/1

Alamat: 172.19.2.2 255.255.0.0

5. Interface Serial $0 / 2 / 0$ 


\section{Alamat: 172.20 .2 .2 255.255.0.0 \\ 6. Interface Serial $0 / 2 / 1$ \\ Alamat: 172.21.2.2 255.255.0.0}

Berikut adalah perintah konfigurasi pada salah satu interface yang digunakan diatas, yaitu pada interface Serial $0 / 0 / 0$.

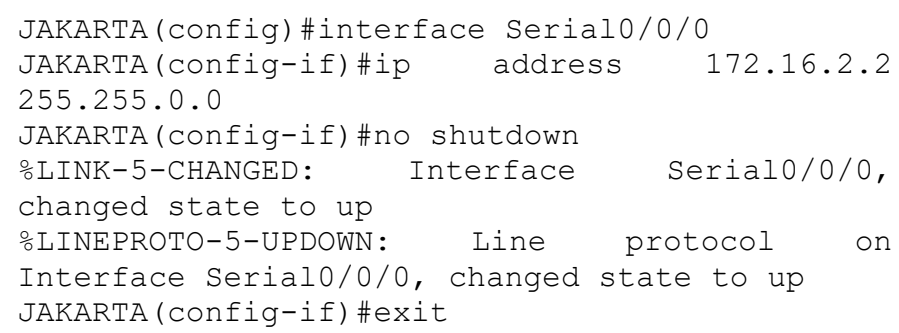

Untuk konfigurasi pada interface yang lain, menggunakan perintah yang identik, namun dengan alamat yang berbeda. Pusat.

Berikutnya adalah konfigurasi EIGRP di Router Kantor

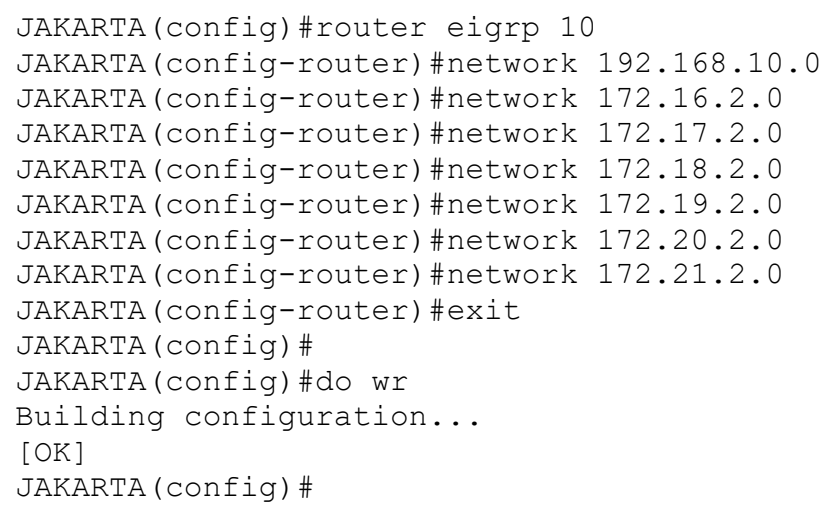

2) Konfigurasi Router Pada Jaringan Kantor Cabang Medan. Konfigurasi umum untuk Router yang ada di kantor-kantor cabang berisikan perintah yang identik. Berikut merupakan contoh konfigurasi yang diberikan di kantor cabang Medan

Diawali dengan perintah untuk masuk ke mode konfigurasi umum yaitu Privilidge Exec Mode pada Cisco IOS yang terdapat pada Router di sisi Kantor Cabang Medan untuk melakukan serangkaian konfigurasi yang diperlukan.

Router>enable

Router\#conf $t$

Enter configuration commands, one per line. End with CNTL/Z.

Router(config) \#hostname MEDAN

Selanjutnya melakukan konfigurasi pada Gateway Interface untuk perangkat yang ada di kantor cabang Medan, dan dilanjutkan dengan mengaktifkan Interface tersebut.
255.255 .255 .0

MEDAN (config-if)\#no shutdown

MEDAN (config-if) \#

\%LINK-5-CHANGED: Interface GigabitEthernet0/0, changed state to up

oLINEPROTO-5-UPDOWN: Line protocol on Interface GigabitEthernet0/0, changed state to up

MEDAN (config-if) \#exit

Untuk mengaktifkan interkoneksi dengan jaringan WAN perusahaan, maka perlu mengaktfikan interface penghubung yang berada pada interface Serial $0 / 0 / 0$, dengan perintah berikut:

MEDAN (config)\#interface Serialo/0/0

MEDAN (config-if)\#ip address 172.16 .2 .1

255.255 .0 .0

MEDAN (config-if) \#no shutdown

MEDAN (config-if) \#exit

MEDAN (config) \#do wr

Building configuration...

[OK]

MEDAN (config) \#

Dilanjutkan dengan konfigurasi untuk mengaktifkan dynamic routing protocol EIGRP yang diperlukan, dengan perintah berikut:

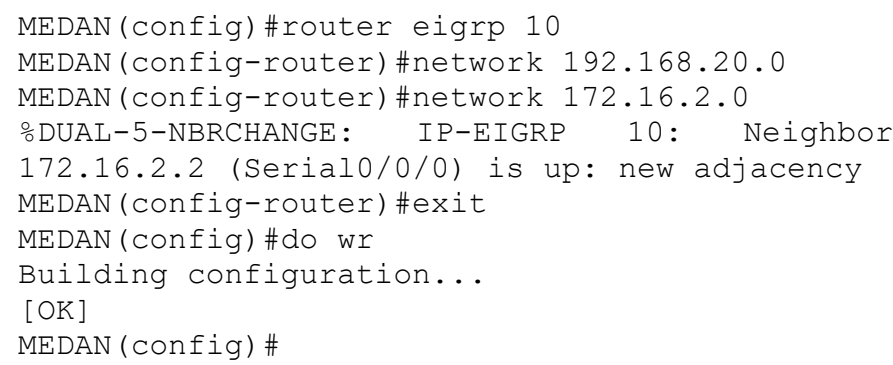

\section{E. Pengujian Awal}

Pengujian diantaranya dilakukan dengan menggunakan ping test (untuk menguji konektifitas antar host) dari Client yang berada di kantor cabang palembang menuju server lensware di kantor pusat melewati di jalur utama (backbone) dengan menggunakan Ping. Hasil pengujian diperlihatkan dalam gambar 3 . 


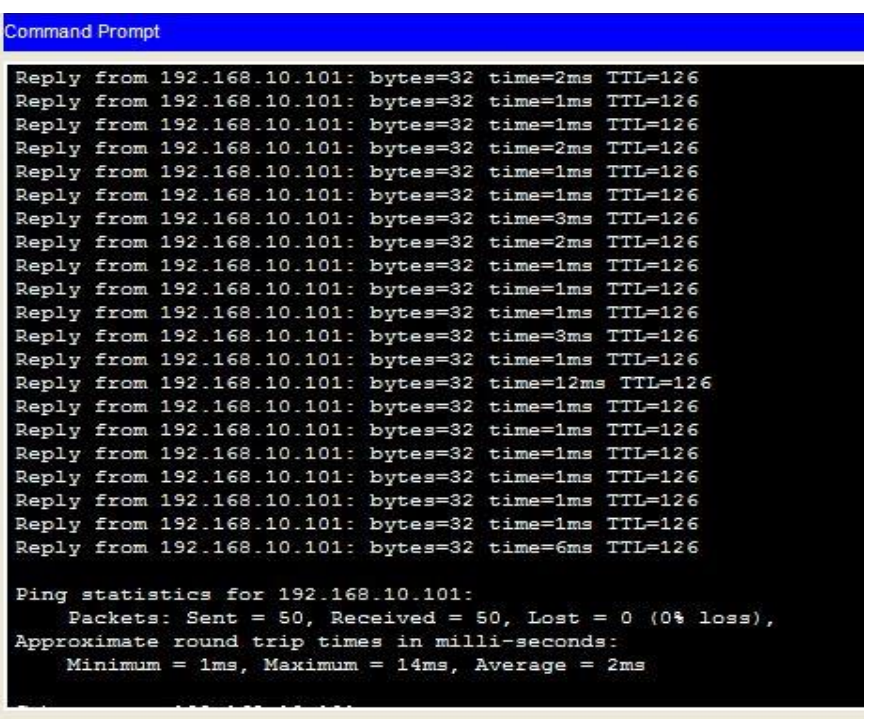

Gambar 3. Ping Test Dari PC di Cabang Palembang ke Server Lensware

Dari hasil pengujian menggunakan ping test, terlihat dari 50 paket data yang dikirimkan dari client di Kantor Cabang Palembang menuju ke alamat IP 192.168.10.101 (alamat Server Lensware di Kantor Pusat Jakarta), seluruh paket (50 paket) tersebut diterima tanpa Loss. Artinya terdapat koneksi antara Client di Kantor Cabang dan Server di Kantor Pusat.

Selanjutnya dilakukan Pengujian yang dilakukan dengan menggunakan test ping dari Client yang berada di kantor cabang bali menuju server E-Mail ( Zimbra ) di kantor pusat melewati di jalur utama (backbone) dengan menggunakan Ping. Hasil pengujian dapat dilihat pada gambar 4.

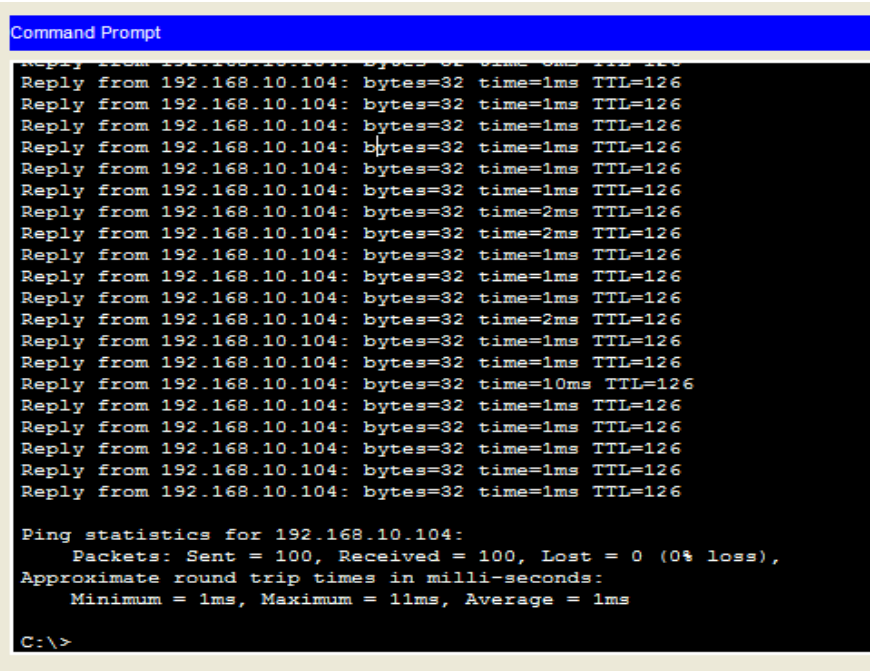

Gambar 4. Ping Test Dari PC di Cabang Bali ke Server E-mail Zimbra

Dengan metode Ping yang hampir sama, namun kali ini dengan mengirim paket data yang lebih banyak yaitu 100 kali, terlihat bahwa server Email (Zimbra) yang terdapat di kantor Pusat (IP Address 192.168.10.104) dapat menerima keseluruhan paket yang dikirim dari Kantor Cabang Bali, sehingga dapat diindikasikan bahwa telah terbentuk konektivitas yang dibutuhkan antara Kantor Cabang Bali dan
Kantor Pusat Jakarta.

\section{F. Pengujian Akhir}

Setelah pemberian konfigurasi di masing-masing Router kantor pusat dan kantor-kantor cabang, yang dilanjutkan dengan pengujian interkoneksi. Hasil keseluruhan dari pengujian diperlihatkan dalam tabel 1 .

TABLE I. HASIL PING TEST KeSEluRUhan

\begin{tabular}{|l|l|c|c|c|}
\hline \multirow{2}{*}{ Pengirim } & \multirow{2}{*}{ Penerima } & \multicolumn{3}{c|}{ Data } \\
\cline { 3 - 5 } & & Sent & Received & Lost \\
\hline Medan01 & Database Server & 20 & 20 & 0 \\
\hline Palembang01 & Web Server & 20 & 20 & 0 \\
\hline Bandung01 & Mail Server & 20 & 20 & 0 \\
\hline Jakarta01 & Makassar01 & 20 & 20 & 0 \\
\hline Jogja01 & Medan01 & 20 & 20 & 0 \\
\hline Bali01 & Bandung01 & 20 & 20 & 0 \\
\hline Makassar01 & Jogja01 & 20 & 20 & 0 \\
\hline
\end{tabular}

Dari tabel 1 dapat dilihat bahwa antara Kantor Cabang sebagai client dengan server-server yang ada di kantor Pusat, telah terbentuk konektivitas yang dibutuhkan. Sebagai contoh, antara salah satu client di kantor Cabang Medan yang berinisial Medan01, ketika mengirim 20 kali paket Ping menuju Database Server yang ada di kantor pusat, kesemuanya dapat diterima tanpa ada Loss. Hal yang sama juga terlihat untuk uji konektivitas antara kantor cabang dengan kantor cabang, misalnya antara client Jogja01 dengan Medan01, memperlihatkan keberhasilan dalam pengiriman 20 kali paket ping tanpa Loss.

Berikutnya adalah skema penambahan jaringan kantor cabang, dimana hanya diperlukan penambahan network address dari network local kantor cabang dengan network public yang terhubung dengan router kantor pusat. Ujicoba penambahan kantor cabang baru pada infrastruktur jaringan yang berjalan, router kantor cabang baru di hubungkan dengan router kantor pusat sebagai sentral dari router cabang yang lain. Konfigurasi Router pada kantor cabang baru yang menggunakan protokol dynamic routing EIGRP, diperlihatkan dalam gambar 5 .

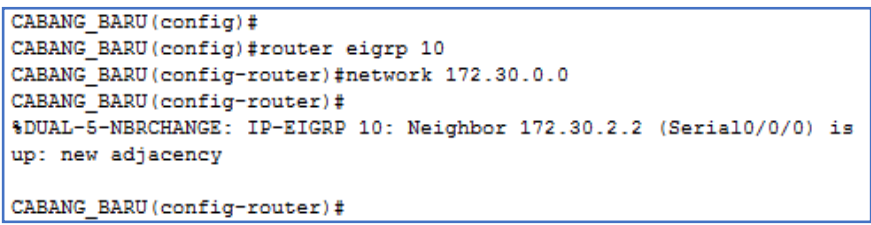

Gambar 5. Konfigurasi EIGRP Router Cabang Baru

Untuk konfigurasi tambahan pada Router sentral yang ada di kantor pusat Jakarta setelah adanya penambahan kantor cabang baru, diperlihatkan pada gambar 6 .

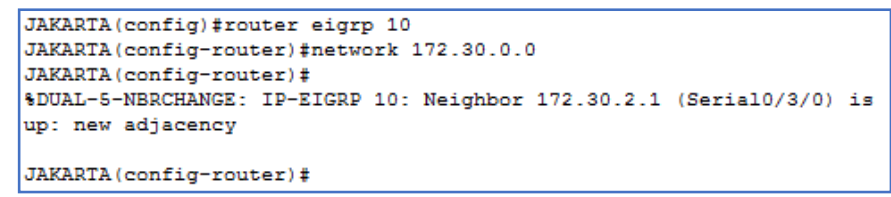

Gambar 6. Konfigurasi EIGRP Router Jakarta

Pada gambar 5 dan gambar 6 didapatkan hasil dengan 
menggunakan dynamic routing, dimana konfigurasi router hanya perlu di lakukan dengan 2 router saja yaitu: router yang berisikan jaringan yang baru dan salah satu router yang berisikan jaringan yang sedang berjalan, hanya dengan saling mengarahkan (routing) antar router tersebut semua jaringan yang terhubung ke jaringan yang lama bisa terhubung dengan router yang berisikan jaringan yang baru, tanpa perlu melakukan konfigurasi routing terhadap semua router yang ada. Sedangkan untuk metode static routing, semua router yang saling terhubung harus dikonfigurasi, agar dapat mentransmisikan paket data dari satu router ke router yang lain.

\section{PENUTUP}

Penerapan dynamic routing membuat infrastruktur jaringan PT Timur Raya Lestari menjadi lebih fleksibel terhadap adanya perubahaan jaringan yang mungkin akan terjadi nantinya seiring perkembangan wilayah bisnis perusahaan. Dengan adanya penerapan protokol dynamic routing mempermudahkan pembukaan cabang baru PT Timur Raya Lestari dari segi jaringan di kantor cabang baru, maupun keseluruhan jaringan yang dimiliki PT Timur Raya Lestari.

Dari seluruh hasil pengujian diperoleh konektivitas yang diperlukan baik antara kantor pusat dengan kantor cabang, maupun antara kantor cabang dengan kantor cabang yang lain. Disamping itu, penambahan kantor cabang baru juga dapat berintegrasi dengan jaringan komputer yang sudah berjalan sebelumnya.

Untuk penelitian berikutnya, disarankan untuk melakukan simulasi antar cabang dengan menggunakan protokol dynamic routing yang lain, misalnya OSPF. Disamping itu perlu adanya monitoring software seperti PRTG untuk memonitor setiap perangkat jaringan untuk evaluasi dan mengendalikan setiap perangkat jaringan, serta perlu adanya maintenance setiap bulan supaya kinerja perangkat jaringan bisa bekerja optimal. Dari segi keamanan sebaiknya pada routing EIGRP untuk setiap router menggunakan EIGRP Authentication agar proses pertukaran data setiap Router bersifat pribadi atau khusus supaya menjadikan infrastruktur jaringan perusahaan menjadi lebih aman.

\section{UCAPAN TERIMA KASIH}

Tim peneliti mengucapkan terima kasih kepada segenap manajemen dan karyawan PT. Timur Raya Lestari atas kesediaan memberikan data dan informasi yang dibutuhkan untuk penelitian ini.

\section{REFERENSI}

[1] S. Sirika and S. Mahajine, "Survey on Dynamic Routing Protocols," Int. J. Eng. Res. Technol., vol. 5, no. 01, pp. 10-14, 2016.

[2] T. D. Purwanto, "Analisis Kinerja Dynamic Routing pada Protokol Routing EIGRP untuk Menentukan Jalur Terbaik dengan Diffusing Update Algorithm (DUAL)," JUITA J. Inform., vol. 6, no. 2, pp. 8998, 2018.

[3] O. N. Georgina, O. H. Chukwuchebe, and D. M. Rosemary, "Simulation Based Appraisal Study Of OSPF And EIGRP For Effective Communication," FUDMA J. Sci., vol. 2, no. 1, pp. 89-98, 2018.

[4] A. Syukur and L. Julianti, "Simulasi Pemanfaatan Dynamic Routing Protocol EIGRP Pada Router di Jaringan Universitasi Islam Riau Beserta Autentikasinya," J. Teknol. Inf. dan Ilmu Komput., vol. 5, no. 1, p. 23, 2018.

[5] I. Satria and A. S. Budiman, "Perancangan EIGRP Routing Protocol Untuk Konektivitas Jaringan Komputer Pada Kantor Cabang Baru PT. AIA Financial," J. Tek. Inform. (JIKA), Univ. Muhammadiyah Tangerang, vol. 3, no. 2, pp. 65-72, 2019.

[6] www.tutorialspoint.com, "DCN - Network Layer Routing," 2019. [Online]. Available: https://www.tutorialspoint.com/data_communication_computer_netw ork/network_layer_routing.htm.

[7] U. Verawardina, "Analisis Perbedaan Peformance dan Quality Of Service ( QoS ) Antara EIGRP dengan OSPF ( Studi Kasus Menggunakan 6 Router Melalui GNS 3 dan Wireshark )," Int. J. Nat. Sci. Eng., vol. 2, no. 1, pp. 10-19, 2018.

[8] C.-H. (John) Wu and J. D. Irwin, Introduction to Computer Networks and Cybersecurity. Boca Raton, FL: CRC Press (Taylor \& Francis Group, LLC), 2013.

[9] A. Z. Al Ghivani, "Studi Perbandingan Routing Protokol BGP Dan EIGRP, Evaluasi Kinerja Performansi Pada Autonomous System Berbeda," J. Sist., vol. 7, pp. 95-105, 2018.

[10] P. Kalamani, M. V. Kumar, M. Chithambarathanu, and R. Thomas, "Comparison of RIP , EIGRP , OSPF , IGRP Routing Protocols in Wireless Local Area Network ( WLAN ) by using OPNET Simulator tool - A Practical Approach," IOSR J. Comput. Eng., vol. 16, no. 4, pp. 57-64, 2014.

[11] J. Deng, S. Wu, and K. Sun, Comparison of RIP , OSPF and EIGRP Routing Protocols based on OPNET. ENSC 427: Communication Networks. Final project. Simon Fraser University, 2014.

[12] V. Vetriselvan, P. R. Patil, and M. Mahendran, "Survey on the RIP, OSPF, EIGRP Routing Protocols," in (IJCSIT) International Journal of Computer Science and Information Technologies, 2014, pp. 10551065.

[13] E. Tetz, Cisco Networking All-in-One For Dummies. Hoboken, NJ: John Wiley \& Sons, Inc, 2011.

[14] K. D. Steward III and A. Adams, Designing and Supporting Computer Networks - CCNA Discovery Learning Guide, Part I: Concepts. Indianapolis: Cisco Press, 2008. 